Gut, 1985, 26, 95-100

\title{
Histological appearances of oesophagus, antrum and duodenum and their correlation with symptoms in patients with a duodenal ulcer
}

\author{
R J EARLAM, J AMERIGO, T KAKAVOULIS, AND D J POLLOCK \\ From the London Hospital, Whitechapel, London E1
}

SUMmARY Clinical data and histology from the oesophagus, gastric antrum, and duodenum were collected from 36 patients undergoing surgery for duodenal ulcer. Gastritis was present in $94 \%$ of the patients (25\% of atrophic type), oesophagitis in $72 \%$ and duodenitis in $39 \%$. Abnormal biopsies were present from all three sites in $33 \%$ of the patients. Only one patient showed three normal biopsies. The low incidence of duodenitis does not support the theory that duodenitis is part of the same spectrum as duodenal ulcer. Heartburn was related to the presence of gastritis $(100 \%)$ and oesophagitis (76\%) but not to duodenitis (52\%). No relationship was found between the length of history, severity of pain, and histological abnormalities.

The correlation of endoscopic appearances and histology of the upper gastrointestinal tract is well established, ${ }^{1-3}$ but papers dealing with the relationship of symptoms and histology have either been inconclusive or shown no association. ${ }^{4-7}$ Fewer reports have correlated symptoms, the histology of oesophagus, stomach, and duodenum and their relationship to each other in biopsies taken simultaneously. ${ }^{8}$ The purpose of this study was to assess whether there was a correlation between the symptoms of duodenal ulceration, severe enough to require operation, and the microscopical appearances of the duodenum, antrum, and oesophagus in biopsies taken at the time of surgery during a truncal vagotomy and pyloroplasty.

\section{Methods}

\section{PATIENTS}

Thirty six patients were studied, 26 men and 10 women with a mean age of 43.5 years (range 19-71 years). All required surgery for duodenal ulcer, which had been diagnosed either radiologically or by endoscopy and confirmed at operation after being unsuccessfully treated medically; only one patient (no 11) was treated preoperatively with cimetidine, because the drug became available towards the end

Address for correspondence: Mr Richard Earlam, The London Hospital, Whitechapel, London E1 1BB.

Received for publication 12 March 1984 of the study. Thirty two patients had a truncal vagotomy and pyloroplasty and the remainder a Polya partial gastrectomy. In six an associated hiatus hernia shown by radiology preoperatively was corrected at the same time (nos 3, 6, 20, 25, 27, 34). Data were collected concerning years of history, the frequency of heartburn and gastro-oesophageal reflux and the amount of waking with night pain using a questionnaire previously described. ${ }^{10}$

The number of years that the patient had suffered indigestion, pain, or heartburn was recorded. Heartburn was graded as 0 -none at all, 1-infrequently, 2-4 to 5 episodes each week and 3-occurring every day in a bad week of indigestion. Acid regurgitation to the mouth was arbitrarily graded 0 if it was infrequent and occurred only on postural changes and + if it always followed lying flat in bed. Night waking by duodenal ulcer pain or heartburn was graded 1-7 on the basis of how frequently a patient was awoken in any one bad week during an attack of indigestion.

HISTOLOGY (Figs 1-3)

Biopsies were taken from the oesophagus ${ }^{11}$ within the lower $5 \mathrm{~cm}$ under direct vision and from the antral and duodenal ends of a pyloroplasty. The oesophageal biopsies, usually single but often multiple, were largely being taken through a rigid oesophagoscope with a Chevalier Jackson biopsy forceps which has a $3 \mathrm{~mm}$ cup. The last two were full thickness biopsies at least $0.5 \mathrm{~cm}$ long from each end 


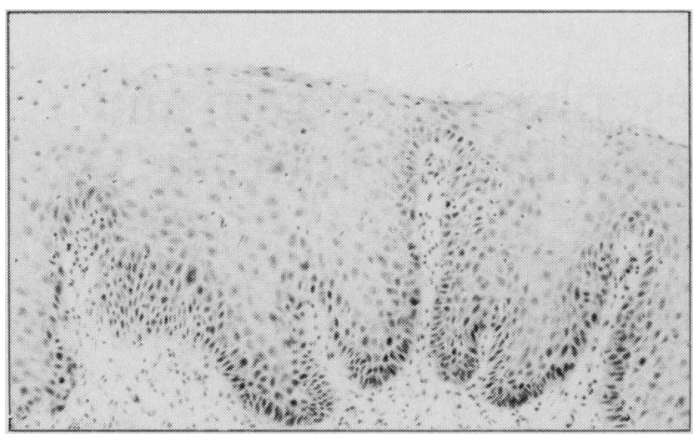

Fig. 1 Moderate oesophagitis: showing increase in thickness of the basal layer with mitoses quite numerous. Papillae approach the surface. Inflammatory cells many of them polymorphs are present both in and beneath the epithelium. (Haematoxylin and eosin $\times 20$ original magnification).

of a pyloroplasty, which was always between 5 and 7 $\mathrm{cm}$ long. The specimens were fixed in formol saline, orientated by a dissecting microscope before embedding and sections were stained with haematoxylin and eosin. Histological appearances were independently assessed by two pathologists (DJP and JA) without knowledge of the clinical data. Oesophageal mucosa was graded by a modified classification ${ }^{4}$ from normal mucosa to severe oesophagitis, ${ }^{12} 13$ including assessment of acute inflammatory infiltrate of the epithelium. The grades were normal, mild, moderate, or severe. Antral and duodenal mucosa were graded using the criteria of Whitehead et al. ${ }^{14} 15$ Duodenitis was graded $0,1,2$, and 3 in increasing severity. The different types of gastritis are detailed in the Table.

\section{Results}

The clinical data and histological findings in the 36 patients are listed in the Table.

\section{(1) Histology alone}

Twelve (33\%) had abnormal biopsies from all three sites, but one patient showed three normal biopsies. Thirty four patients (94\%) showed histological evidence of gastritis; nine $(25 \%)$ of the atrophic type. Fourteen $(39 \%)$ had duodenitis and $26(72 \%)$ oesophagitis; 12 with concomitant duodenitis. In six patients a hiatus hernia was found radiologically as well as the duodenal ulcer and in four of these oesophagitis was present, gastritis in five and duodenitis in only one, but none had abnormalities of all three sites.

\section{(2) Symptoms correlated with histology}

(a) Years of history

Nine patients showing some degree of atrophic gastritis had an average 15 years history (range 1-27 years), whereas 24 patients with superficial gastritis had an average of 12.6 years of history (range 2-40 years). Two with normal gastric mucosa had a history of 13 and 30 years. No relationship was found between the degree of inflammation in the oesophagus, stomach, or duodenum and the duration of symptoms.

\section{(b) Heartburn}

A total of 21 patients (58\%) had heartburn. Histologically five had a normal oesophagus; all 21 had abnormal antral mucosa and 12 had an abnormal duodenal mucosa. Of 12 patients with all three abnormal biopsies eight (67\%) had heartburn. Two patients with a normal biopsy of the antrum had neither heartburn nor acid regurgitation. Of 34 patients with gastritis $21(62 \%)$ presented with heartburn. Of 26 patients with oesophagitis 16 (62\%) had heartburn, but five (19\%) patients with a normal oesophageal mucosa also had this symptom. Of 14 patients with duodenitis nine $(64 \%)$ had heartburn, conversely $12(86 \%)$ patients with a normal duodenal mucosa presented with heartburn.

Heartburn was associated with microscopical oesophagitis in about three-quarters of the patients and a normal oesophageal mucosa in the remainder. Only two-thirds of the patients with oesophagitis had heartburn. Heartburn was never found in the presence of a normal antrum; on the contrary all patients with heartburn had some form of gastritis and more than two-thirds had duodenitis.

\section{(c) Acid regurgitation}

Eleven patients had varying degrees of acid regurgitation to the throat associated with heartburn. Six had mild oesophagitis, one had moderate changes but four were normal. Four had chronic superficial gastritis, five had chronic active superficial gastritis, and two had moderate or severe chronic active atrophic gastritis, six had a normal duodenal mucosa; two had grade one changes, one grade two and two grade three. There appeared to be no correlation between acid regurgitation and histological appearances.

\section{(d) Night pain}

All patients but two presented with night pain of variable degree. No correlation was found between the histological lesions and frequency of waking at night. 

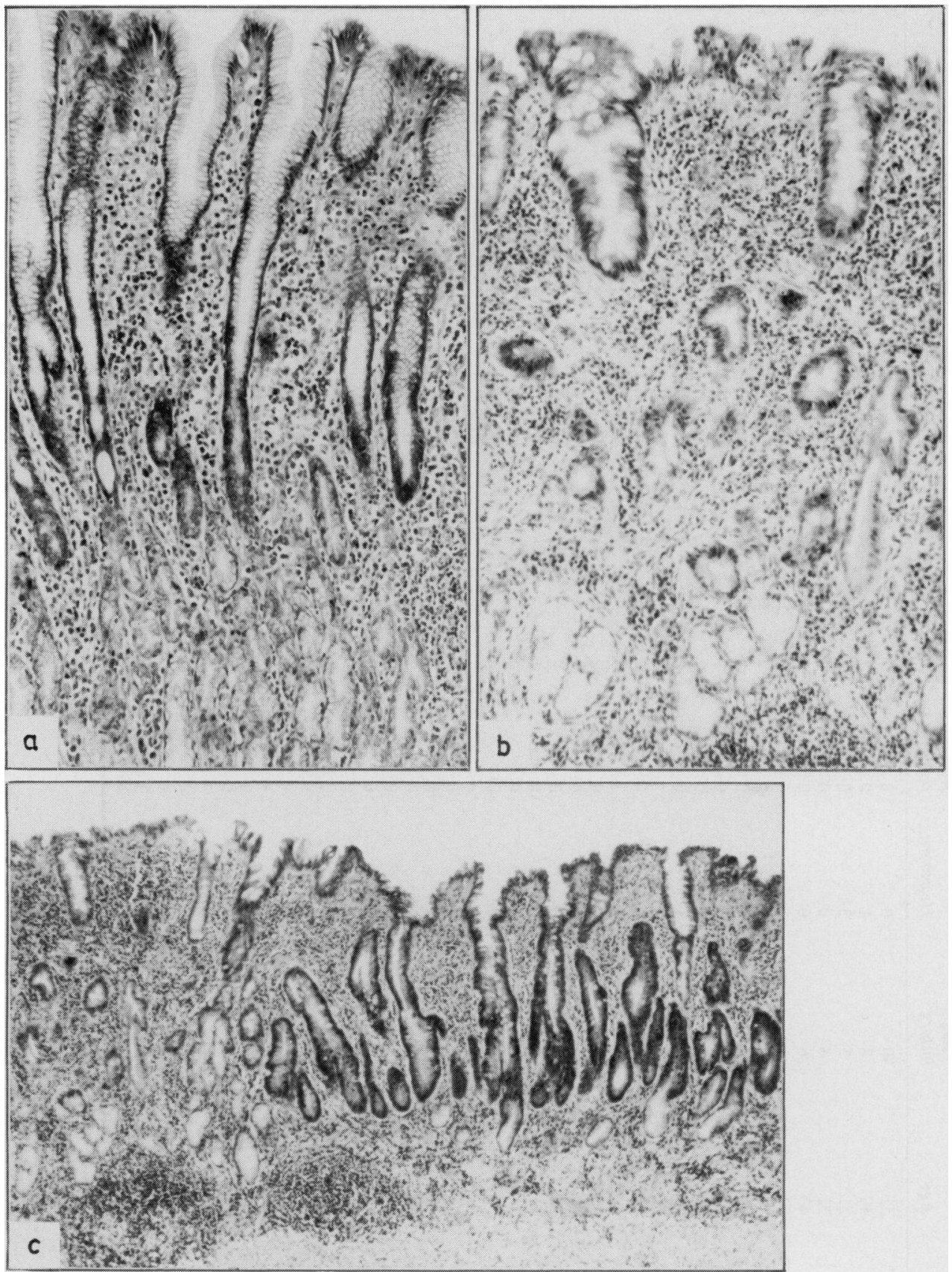

Fig. 2 Gastritis: (a) chronic superficial gastritis. The inflammatory infiltrate consists mainly of lymphocytes and plasma cells and is superficial. Surface epithelium and deep glands are preserved. (Haemotoxylin and eosin $\times 40$ original magnification). (b) Chronic active superficial gastritis. Inflammatory cells are involving the surface epithelium and there are polymorphs amongst them. (Haematoxylin and eosin $\times 40$ original magnification). (c) Chronic active severe atrophic gastritis: there is loss of deep gastric glands. An intense inflammatory infiltrate mainly lymphocytes affects full thickness of the mucosa. (Haematoxylin and eosin $\times 20$ original magnification). 


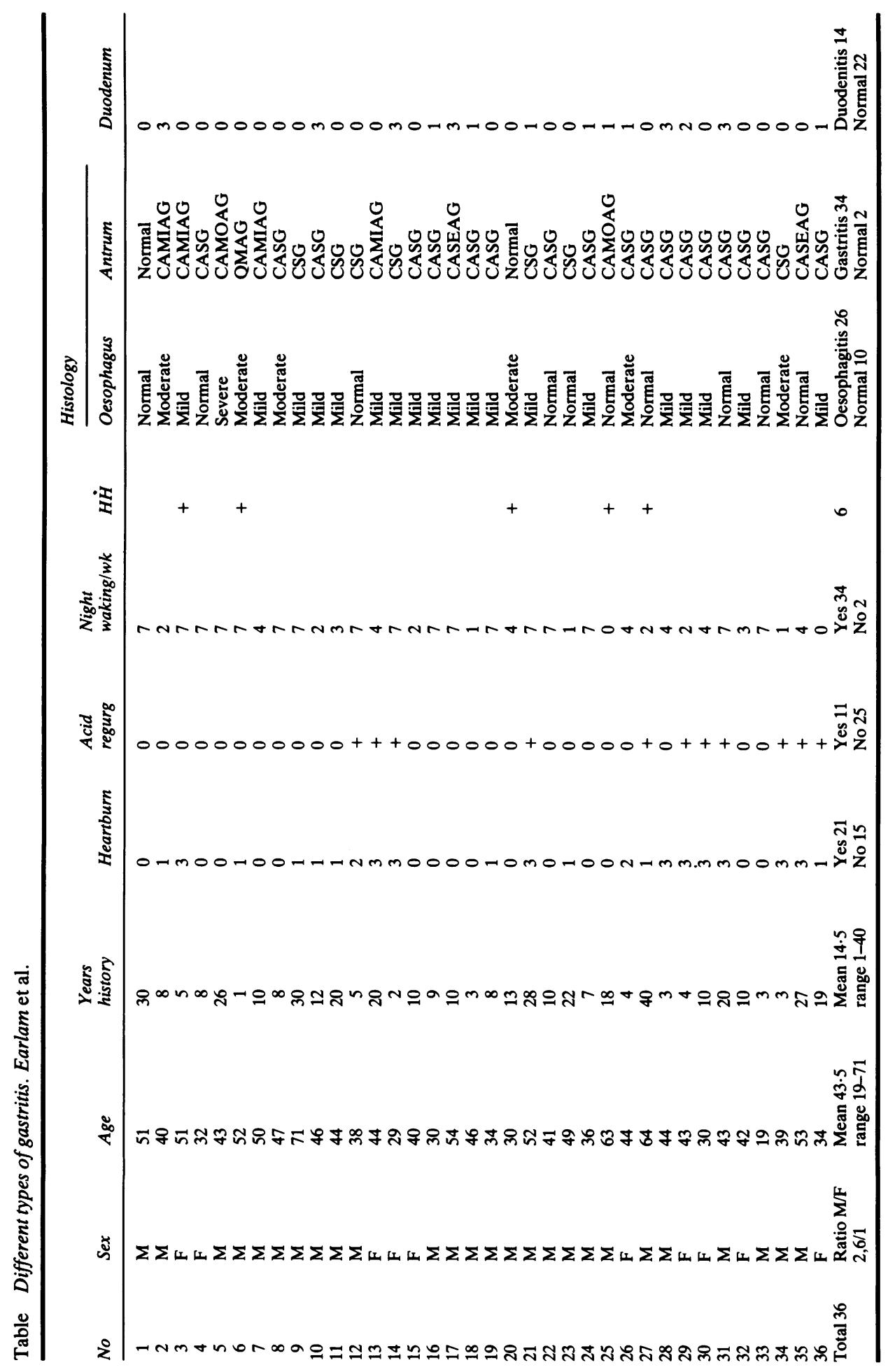

$\operatorname{nna\rightarrow an}$ 


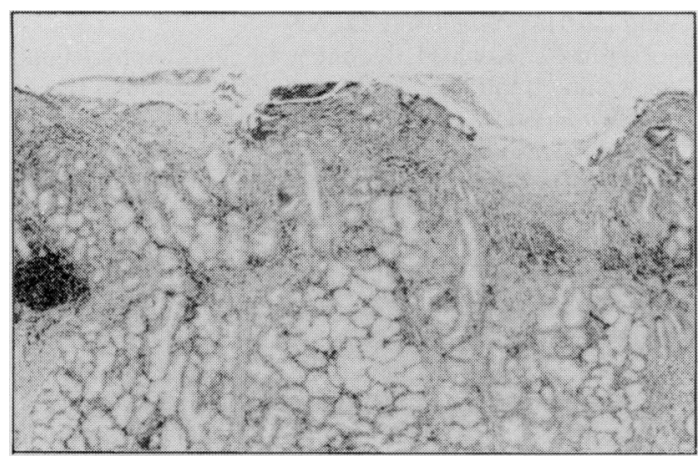

Fig. 3 Duodenitis, severe: there is ulceration and inflammatory cells are numerous with polymorphs predominant near the surface lymphocytes. (Haematoxylin and eosin $\times 20$ original magnification).

\section{Discussion}

The most striking finding of our study is the high incidence of antral gastritis (94\%). Moraes-Filho and Bettarello ${ }^{9}$ have shown the incidence of gastritis in patients with duodenal ulcer as $41 \%$. This difference is probably due to the fact that in previous work the gastric biopsies were taken without fibreoptic control and were not always within $4 \mathrm{~cm}$ of the pylorus. Additionally the present series consisted only of those patients with severe pain that required surgery. On the other hand, the incidence of oesophagitis in our series does not differ from the previous findings.

Although there is a good association between peptic ulcer and antral gastritis, ${ }^{16}$ the correlation between duodenal ulcer and duodenitis is not so close. Like Classen et $\mathbf{a l}^{17}$ we have found duodenitis in about $40 \%$ of patients with duodenal ulcer. The poor association of duodenitis with duodenal ulcer does not support the hypothesis of some authors that duodenitis is a precursor of duodenal ulcer or that it is a part of the same pathophysiological spectrum. ${ }^{1} 18-20$

No relationship was found between years of history, severity of pain and histology. Nocturnal waking ${ }^{10}$ was accepted as an important method of assessing the severity of the disease process but there was no correlation between this and histological appearances either. The presence of a hiatus hernia shown radiologically did not correlate either with clinical symptoms or histology. Gastrooesophageal reflux occurred to an equal extent in patients whether a hiatus hernia was shown or not and this probably occurs because the majority of patients with a duodenal ulcer have a mano- metrically demonstrable hernia. ${ }^{21}$ We agree with Volpicelli $e \mathrm{al}^{8}$ that the first event in the production of heartburn could be reflux of duodenal juices into the stomach where bile and pancreatic juice combined can produce gastritis as seen both in postgastrectomy patients and experimentally. ${ }^{22} 23$ The second step could be a reflux of this duodenal juice from the stomach to the oesophagus giving rise to heartburn. This retrograde movement of bile through duodenogastric reflux has been recently reviewed. ${ }^{24}$

The microscopical appearances of the duodenum and the oesophagus are probably not of any importance for clinical decision taking in the management of patients. A controversial suggestion is that mucosal biopsies of the stomach and oesophagus should only be taken to exclude malignancy. Duodenal carcinoma is rare, so this will not apply to duodenal mucosal biopsies. Perhaps an exception to this rule would be biopsies taken for research purposes to see whether they are of any practical importance in the management of patients and actually alter any decision already made on clinical, radiological or endoscopic evidence.

The development of gastric cancer after partial gastrectomy is well recognised and may possibly be because of the gastritis that is usually present, ${ }^{25} 26$ but the incidence is probably no more than would be expected in the normal population. ${ }^{27}$ It must be presumed that a vagotomy and drainage procedure may also predispose to the later development of gastric cancer because bile reflux and gastritis occur, but no epidemiological studies have been done and the necessary time interval since surgery was performed has not yet elapsed. The relationship of gastritis to gastric carcinoma remains an unresolved problem.

If there is no correlation between the symptoms of duodenal ulceration and the histological appearances of the mucosa at different sites, the clinician must ask himself what is the purpose of taking biopsies. Both gastritis and duodenitis can occur in symptomless people. ${ }^{28-30}$

At the moment it does not seem likely that the histological appearances of the gastric mucosa change the practical management of patients with duodenal ulceration.

\section{References}

1 Joffe SN, Lee FD, Blumgart LH. Duodenitis. Clin Gastroenterol 1978; 7: 635-50.

2 Stephen JG, Lesna M, Venables CW. Endoscopic appearances and histological changes in ulcerassociated duodenitis. Br J Surg 1978; 65: 438-41. 
3 Thompson $\mathrm{H}$, Holme G. The diagnosis of duodenitis. Gut 1974; 15: 842-3.

4 Ismail-Beigi F, Horton PF, Pope CE. Histological consequences of gastroesophageal reflux in man. Gastroenterology 1970; 58: 163-74.

5 Johnson LF, Demeester TR, Haggitt RC. Esophageal epithelial response to gastroesophageal reflux. Am J Dig Dis 1978; 23: 498-509.

6 Seefeld U, Krejs GJ, Siebenmann RE, Blum AL. Esophageal histology in gastroesophageal reflux morphometric findings in suction biopsies. Am J Dig Dis 1977; 22: 956-64.

7 Wright RA, Hurwitz AL. Relationship of hiatal hernia to endoscopically proved reflux esophagitis. Am J Dig Dis 1979; 24: 311-13.

8 Volpicelli NA, Yardley JH, Hendrix TR. The association of heartburn with gastritis. Am J Dig Dis 1977; 22: 333-9.

9 Moraes-Filho JPP, Bettarello JP. Lack of specificity of the acid perfusion test in duodenal ulcer patients. Am J Dig Dis 1974; 19: 785-90.

10 Earlam R. A computerized questionnaire analysis of duodenal ulcer symptoms. Gastroenterology 1976; 71: 314-7.

11 Ismail-Beigi F, Pope CE. Distribution of the histological changes of gastroesophageal reflux in the distal esophagus of man. Gastroenterology 1974; 66:1109-13.

12 Winter HS, Madara JL, Stafford RJ et al. Intraepithelial eosinophils: a new diagnostic criterion for reflux esophagitis. Gastroenterology 1982; 83: 818-23.

13 Weinstein WM, Bogoch ER, Bowes KL. The normal human esophageal mucosa: a histological reappraisal. Gastroenterology 1975; 68: 40-4.

14 Whitehead R, Truelove SC, Gear MWL. The histological diagnosis of chronic gastritis in fibreoptic gastroscope biopsy specimens. J Clin Pathol 1972; 25: $1-11$.

15 Whitehead R, Roca M, Meikle DD, Skinner J, Truelove SC. The histological classification of duodenitis in fibreoptic biopsy specimens. Digestion 1975; 13: 129-36.

16 Gear MWL, Truelove SC, Whitehead R. Gastric ulcers and gastritis. Gut 1971; 12: 639-45.

17 Classen M, Koch H, Demling L. Duodenitis: significance and frequency. In: Maratka Z, Ottenjann R, eds. Inflammation in gut. Basel: Karger, 1979; 48-9.

18 Hasan M, Sircus W, Ferguson A. Duodenal mucosal architecture in non-specific and ulcer associated duodenitis. Gut 1981; 22: 637-41.

19 Cotton PB, Price AB, Tighe JR, Beals JSM. Preliminary evaluation of duodenitis by endoscopy and biopsy. Br Med J 1973; 3: 430-3.

20 Schulze S, Pedersen NT, Jorgensen MJ et al. Association between duodenal bulb ulceration and reduced exocrine pancreatic function. Gut 1983; 24: 781-3.

21 Earlam RJ. The gastro-oesophageal junction in patients with duodenal ulceration. Rend Gastroenterol 1972; 4: 69-72.

22 Brooks WS, Wenger J, Hersh T. Bile reflux gastritis. Analysis of fasting and postprandial gastric aspirates. Am J Gastroenterol 1975; 64: 286-91.

23 Eastwood GL. Effect of $\mathrm{pH}$ on bile salt injury to mouse gastric mucosa. A light and electron microscopic study. Gastroenterology 1975; 68: 1456-65.

24 Earlam RJ. Bile reflux and the Roux en $\mathrm{Y}$ anastomosis. Br J Surg 1983; 70: 393-7.

25 Fischer AB, Graem N, Christiansen LA. Causes and clinical significance of gastritis following Billroth II resection for duodenal ulcer. Br J Surg 1983; 70: 322-5.

26 Schrompf E, Serck-Hanssen A, Stadaas J, Aune A, Myren J, Osnes M. Mucosal changes in gastric stump 20-25 years after partial gastrectomy. Lancet 1977; 2: 467-9.

27 Fischer AB, Graem N, Jensen OM. Risk of gastric cancer after Billroth II resection for duodenal ulcer. $\mathrm{Br}$ J Surg 1983; 70: 552-4.

28 Krenning J, Bosman FT, Kuiper G, Van der Wal AM, Lindeman J. Gastric duodenal mucosa in "healthy" individuals. J Clin Pathol 1978; 31: 69-77.

29 Cheli R, Aste H. Duodenitis. Stuttgart: Georg Thieme, 1976: 96.

30 Cheli R, Giacosa A. Inflammatory cell count and identification in chronic non-specific duodenitis. Endoscopy 1977; 9: 91-5. 